\title{
Microsurgical anatomy and approaches around the lateral recess with special reference to entry into the pons
}

\author{
Osamu Akiyama, MD, PhD, ${ }^{1,2}$ Ken Matsushima, MD,1,3 Maximiliano Nunez, MD, ${ }^{4}$ \\ Satoshi Matsuo, MD, PhD, ${ }^{5}$ Akihide Kondo, MD, PhD, ${ }^{2}$ Hajime Arai, MD, PhD, ${ }^{2}$ \\ Albert L. Rhoton Jr., MD, ${ }^{1}$ and Toshio Matsushima, MD, PhD ${ }^{6,7}$ \\ 'Department of Neurological Surgery, University of Florida, Gainesville, Florida; ${ }^{2}$ Department of Neurosurgery, Juntendo \\ University; ${ }^{3}$ Department of Neurosurgery, Tokyo Medical University, Tokyo; ${ }^{5}$ Department of Neurosurgery, Graduate School \\ of Medical Sciences, Kyushu University; ${ }^{6}$ Neuroscience Center, Fukuoka Sanno Hospital; ${ }^{7}$ Graduate School, International \\ University of Health and Welfare, Fukuoka, Japan; and ${ }^{2}$ Department of Neurosurgery, Hospital El Cruce, Buenos Aires, Argentina
}

OBJECTIVE The lateral recess is a unique structure communicating between the ventricle and cistern, which is exposed when treating lesions involving the fourth ventricle and the brainstem with surgical approaches such as the transcerebellomedullary fissure approach. In this study, the authors examined the microsurgical anatomy around the lateral recess, including the fiber tracts, and analyzed their findings with respect to surgical exposure of the lateral recess and entry into the lower pons.

METHODS Ten cadaveric heads were examined with microsurgical techniques, and 2 heads were examined with fiber dissection to clarify the anatomy between the lateral recess and adjacent structures. The lateral and medial routes directed to the lateral recess in the transcerebellomedullary fissure approach were demonstrated. A morphometric study was conducted in the 10 cadaveric heads ( 20 sides).

RESULTS The lateral recess was classified into medullary and cisternal segments. The medial and lateral routes in the transcerebellomedullary fissure approach provided access to approximately $140^{\circ}-150^{\circ}$ of the posteroinferior circumference of the lateral recess. The floccular peduncle ran rostral to the lateral recess, and this region was considered to be a potential safe entry zone to the lower pons. By appropriately selecting either route, medial-to-lateral or lateral-to-medial entry axis is possible, and combining both routes provided wide exposure of the lower pons around the lateral recess.

CONCLUSIONS The medial and lateral routes of the transcerebellomedullary fissure approach provided wide exposure of the lateral recess, and incision around the floccular peduncle is a potential new safe entry zone to the lower pons. https://thejns.org/doi/abs/10.3171/2017.5.JNS17251

KEY WORDS brainstem; cerebellomedullary fissure approach; floccular peduncle; lateral recess; safe entry zone; telovelar approach; anatomy

$\mathrm{T}$ HE lateral recess, involving the lateral part of the fourth ventricle, is a unique structure communicating between the fourth ventricle and the cerebellopontine angle. With development and adoption of the transcerebellomedullary fissure approach, ${ }^{13,14,18-20,23,25,26 \text {, }}$ 29,38 detailed anatomical knowledge of the lateral recess has become important. The addition of a lateral recess incision to cerebellomedullary fissure dissection facilitates cerebellar hemisphere retraction. ${ }^{6,19,22,23}$ The transcerebellomedullary fissure approach was first proposed by one of the senior authors (T.M.), and it was directed toward internal lesions of the fourth ventricle from the foramen of Magendie to avoid a vermis ${ }^{21}$ incision. Based on our surgical experience in this region, we propose the following 2 variations of the transcerebellomedullary fissure approach: the medial route, a conventional cerebellomedullary fissure opening from the midline, and the lateral route, ${ }^{13,26}$ a unilateral cerebellomedullary fissure opening from the inferolateral side and approaching the interior region of the fourth ventricle from the inferolateral side. ${ }^{23}$ Recent reports have stated that even for lesions existing only in the cerebellomedullary cistern, such as vertebral 

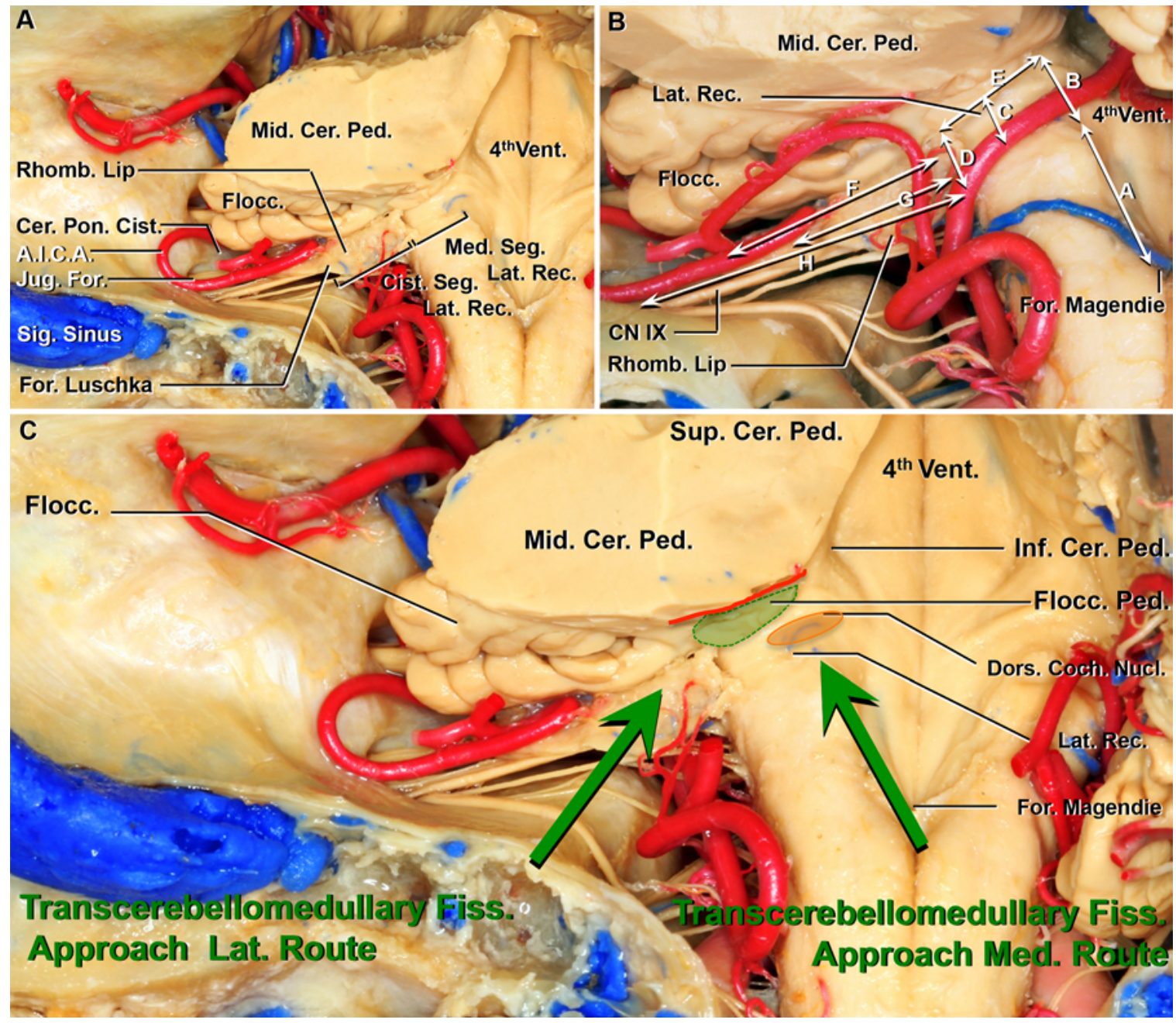

FIG. 1. A: Relationships of the lateral recess in the posterior view. The right hemisphere of the cerebellum has been removed at the level of the middle cerebellar peduncle. The lateral recess consists of the lateral part of the fourth ventricle. It connects laterally with the cerebellopontine cistern through the foramen of Luschka. The lateral recess was classified with the medullary segment and cisternal segment. B: Anatomy and measurements around the lateral recess. The lettered lines indicate the measurements presented in Table 1. C: Surgical approaches around the lateral recess. The medial and lateral routes of the transcerebellomedullary fissure approach (green arrows) provide wide exposure of the lateral recess and the floccular peduncle. By utilizing both routes of the transcerebellomedullary fissure approach, the posteroinferior circumference (red line) of the lateral recess was exposed. The floccular peduncle (green area), rostral to the lateral recess, may be a good option for approaching lesions inside the lower pons. The orange oval shows the dorsal cochlea nucleus. Cer. = cerebellar; Cis. $=$ cistern, cisternal; Coch. = cochlear; Dors. = dorsal; Fiss. = fissure; Flocc. = flocculus, floccular; For. = foramen (of); Inf. = inferior; Jug. = jugular; Lat. = lateral; Med. = medial, medullary; Mid. = middle; Nucl. = nucleus; Ped. = peduncle; Pon. = pontine; Rec. = recess; Rhomb. = rhomboid; Seg. = segment; Sig. = sigmoid; Sup. = superior; Vent. = ventricle.

artery aneurysms, the unilateral cerebellomedullary fissure and lateral recess approaches reduce the need for cerebellar retraction and provide a wide operative field..$^{23}$ For these surgical approaches that involve cerebellomedullary fissure dissection, detailed anatomical understanding of the lateral recess is essential. In addition, with the recent advances in brainstem surgery, the entry zones around the lateral recess have gained more attention..$^{5,710,16}$ Thus far, however, detailed anatomical investigations of the lateral recess and entries into the brainstem around the lateral recess have not been adequately conducted. The present cadaveric study was designed to investigate the microsurgical anatomy of the lateral recess and the surrounding structures, including fiber tracts, for reconsidering the surgical exposure of the lateral recess and for proposing potential approaches into the brainstem around the lateral recess.

\section{Methods}

Ten formalin-perfused adult cadaveric heads were used for morphometric measurements (Fig. 1A and B and Table 1). The arteries and veins were perfused with red and blue silicone rubber (Dow Corning Corp.), Thinner 200 (Dow Corning Corp.), and RTV catalyst (Dow Corning Corp.), and were then dissected using $\times 3$ to $\times 40$ magnification 
TABLE 1. Relationships of the lateral recess

\begin{tabular}{|c|c|c|c|}
\hline Line & Description* & $\begin{array}{l}\text { Average } \\
(\mathrm{mm})\end{array}$ & $\begin{array}{l}\text { Range } \\
(\mathrm{mm})\end{array}$ \\
\hline A & $\begin{array}{l}\text { Length btwn foramen of Magendie \& } \\
\text { lowest point of ventricular aperture of } \\
\text { lateral recess }\end{array}$ & 11.9 & $9.8-14.4$ \\
\hline B & $\begin{array}{l}\text { Width of ventricular aperture of lateral } \\
\text { recess in 4th ventricle }\end{array}$ & 5.9 & $2.8-8.6$ \\
\hline C & Width in middle of medullary segment & 4.5 & $2.6-7.1$ \\
\hline $\mathrm{D}$ & $\begin{array}{l}\text { Width of lateral edge of medullary seg- } \\
\text { ment }\end{array}$ & 4.1 & $2.8-6.5$ \\
\hline$E$ & Length of medullary segment & 8.0 & $5.2-9.3$ \\
\hline $\mathrm{F}$ & Length of cisternal segment & 9.2 & $5.2-15.0$ \\
\hline G & Length of rhomboid lip attached to CN IX & 5.1 & $3.0-7.8$ \\
\hline $\mathrm{H}$ & Length of CN IX & 14.8 & $11.9-20.3$ \\
\hline
\end{tabular}

* See also Fig. 1B.

under an operating microscope (Carl Zeiss AG). Bone dissection was performed with a Midas Rex drill (Medtronic). The dissections followed the surgical procedures step by step. For fiber dissection, 2 cerebella with attached brainstems were perfused with formalin, fixed in alcohol, and then dissected using fiber dissection techniques. ${ }^{36}$

The variations of the transcerebellomedullary fissure approach from the posterior side were investigated for access to the vicinity of the lateral recess (Fig. 1C).

\section{Results}

\section{Segmentation of the Lateral Recess}

The lateral recess is a thin, tunnel-like structure extending laterally at the pontomedullary junction, where the width of the fourth ventricular floor is the widest. ${ }^{28}$ The medial edge of the lateral recess is the ventricular aperture, which communicates with the superior margin of the taeniae, and its lateral edge opens into the cerebellopontine angle, forming the foramen of Luschka. In the present study, the lateral recess was classified as follows: 1) the medullary segment, which was attached to the dorsal medulla, and 2) the cisternal segment, which was located in the cerebellopontine angle and was discontinuous from the medulla (Fig. 1B).

\section{Structural Components of the Lateral Recess}

The lateral recess was mainly formed by the flocculus, floccular peduncle, inferior medullary velum, tela choroidea, rhomboid lip, and floor of the fourth ventricle. Its rostral wall was mainly formed by the flocculus, floccular peduncle, and inferior medullary velum; its caudal wall was formed by the rhomboid lip; and its dorsal wall was formed by the tela choroidea. The ventral wall of the medullary segment was mainly formed by the floor of the fourth ventricle, including the inferior cerebellar peduncle and cochlear nucleus, and the ventral wall of the cisternal segment was mainly formed by the lateral part of the rhomboid lip, which was pouch-shaped and distinct from the medulla (Figs. 2 and 3). The cochlear nucleus formed a prominence on the floor of the fourth ventricle, and the inferior cerebellar peduncle, connecting the medulla and the cerebellum, ran under the nucleus (Fig. 3E). The floccular peduncle projected medially from the flocculus to the medial vestibular, cochlear, and abducens nuclei around the fourth ventricle. The inferior medullary velum, tela choroidea, and rhomboid lip were continuous sheet-like structures, and a clear boundary, the telovelar junction, was situated between the inferior medullary velum and tela choroidea (Fig. 3C and D). Between the tela choroidea and rhomboid lip, a boundary was confirmed microscopically; however, it was not as clear as the telovelar junction. The inferior medullary velum gradually decreased in width along the lateral side, and formed only part of the rostral wall of the lateral recess in the cisternal segment. The majority of the cisternal segment was formed by the rhomboid lip and tela choroidea (Figs. 2D, 3C, and 3D). The rhomboid lip was a sheet-like neural tissue adhering to the medulla in the medullary segment that formed a pouch, which varied greatly in size, in the cisternal segment. The choroid plexus, the only structure inside the lateral recess, arose on the inner surface of the tela choroidea. The choroid plexus extended through the foramen of Luschka to the cerebellopontine angle (Fig. 3B and C).

\section{Neural Relationships}

Cranial nerves (CNs) VII and VIII ran rostroventral to the lateral recess after arising from the lateral edge of the pontomedullary sulcus. CNs IX and X ran ventral to the lateral recess, occasionally with adhesion, after exiting from the retro-olivary sulcus (Fig. 2A and B). The bulges of the ventral and dorsal cochlear nuclei, located on the inferior cerebellar peduncle at the pontomedullary junction within the lateral recess, could be observed when the lateral recess was opened (Fig. 3E). The tonsillar peduncle, where the tonsil communicates with the hemisphere, was situated rostroventral to the lateral recess (Fig. $3 \mathrm{C}$ and D).

The cerebellomedullary fissure was formed by the medulla, lateral recess, and cerebellum. The lateral recess formed the ventral wall of the uppermost portion of the cerebellomedullary fissure. When following the lateral edge of the tonsillobiventral fissure downward, the cisternal segment of the lateral recess in the cerebellopontine angle was exposed (Fig. 3F).

\section{Vascular Relationships}

The main arteries coursing around the lateral recess were the posterior inferior cerebellar artery (PICA) and anterior inferior cerebellar artery (AICA). The tonsillomedullary segment of the PICA usually passed below the lateral recess, entering into the cerebellomedullary fissure after passing CNs IX-XII. After forming the caudal loop near the lower pole of the tonsil, its telovelotonsillar segment ascended to reach the lateral recess again, and formed the cranial loop around the medullary segment of the lateral recess. During this course, some of the PICA's perforators supplied the tela choroidea and the choroid plexus of the lateral recess. The flocculopeduncular segment of the AICA ran near the cisternal segment of the lateral recess after forming the meatal loop around the in- 

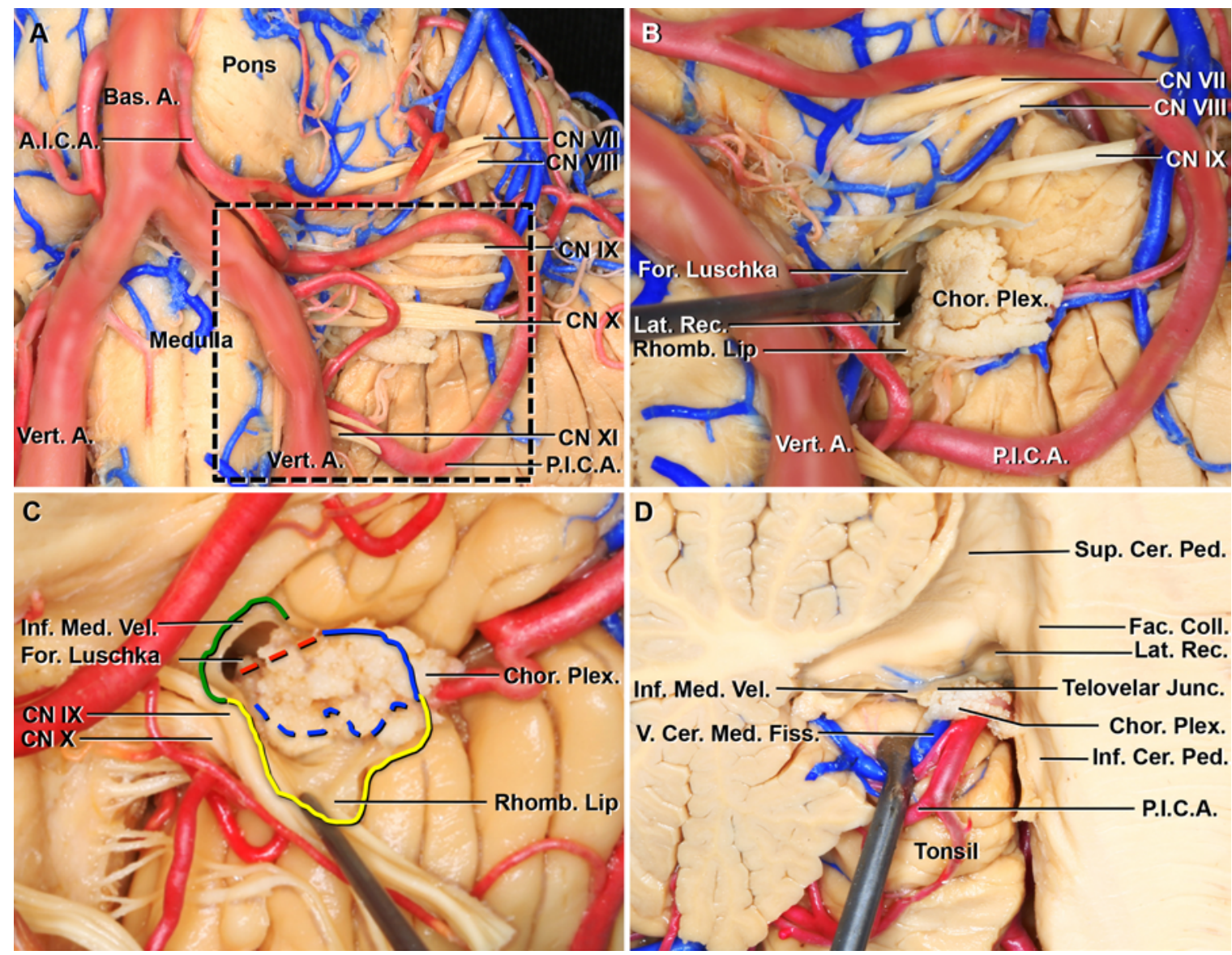

FIG. 2. A: Anterolateral view of the petrosal surface of the cerebellum and the brainstem. Structures ventral to the lateral recess include the flocculus and CNs VII-XI. The foramen of Luschka is hidden behind CNs IX and X. The black rectangle outlines the area shown in B. B: CN X has been removed. The rhomboid lip is a thin layer of neural tissue. The rhomboid lip has been retracted anteriorly to open the foramen of Luschka. The choroid plexus protrudes from the lateral recess. C: Enlarged anterior view. $\mathrm{CNs}$ IX and $\mathrm{X}$ have been reflected inferiorly. The relationships and borders between the tela choroidea, rhomboid lip, and inferior medullary velum are shown. The green line shows the edge of the inferior medullary velum. The yellow line shows the edge of the rhomboid lip. The solid blue line shows the tela choroidea. The red broken line shows the telovelar junction. The broken blue line shows the junction between the rhomboid lip and the tela choroidea. D: Medial view of the lateral recess in the midline. The vein of the cerebellomedullary fissure courses outside of the lateral recess. The anterior wall of the medullary segment is formed by the inferior medullary velum. The posterior wall is formed by the rhomboid lip and the tela choroidea. A. = artery; Bas. = basilar; Chor. = choroid; Coll. = colliculus; Fac. = facial; Junc. = junction; Plex. = plexus; V. = vein (of); Vel. = velum; Vert. = vertebral.

ternal acoustic meatus. A few branches from this segment occasionally supplied the choroid plexus in the lateral recess and projecting from the lateral recess (Fig. 3A).

Other veins coursing around the lateral recess included the vein of the cerebellomedullary fissure (also known as the vein of the lateral recess) and the vein of the inferior cerebellar peduncle. The vein of the cerebellomedullary fissure ran rostral to the lateral recess, and the vein of the inferior cerebellar peduncle ran caudal to the lateral recess. The vein of the cerebellomedullary fissure originated at the lateral edge of the nodule and uvula, and passed laterally along the rostral edge of the medullary segment of the lateral recess and then ventral to the flocculus to reach the cerebellopontine angle. This vein never ran inside the lateral recess. The vein of the inferior cerebellar peduncle crossed the inferior cerebellar peduncle caudal to the medullary segment of the lateral recess, and it coursed on the peduncle parallel to the curved inferolateral margin of the fourth ventricle. The vein of the inferior cerebellar peduncle connected with the median posterior medullary vein lateral to the foramen of Magendie and with the lateral medullary vein lateral to the medulla. After ascending along the inferolateral edge of the fourth ventricle, the vein of the inferior cerebellar peduncle often coursed along the caudal edge of the lateral recess to reach the cerebellopontine angle (Fig. 3B).

\section{Fiber Connections Around the Lateral Recess}

The fiber tracts running through and near the lateral recess were the vestibular and cochlear nerves, inferior and middle cerebellar peduncles, and floccular peduncle (Fig. 4A). The fiber tracts that formed the ventral wall of the lateral recess were mainly the cochlear and vestibular nerves 

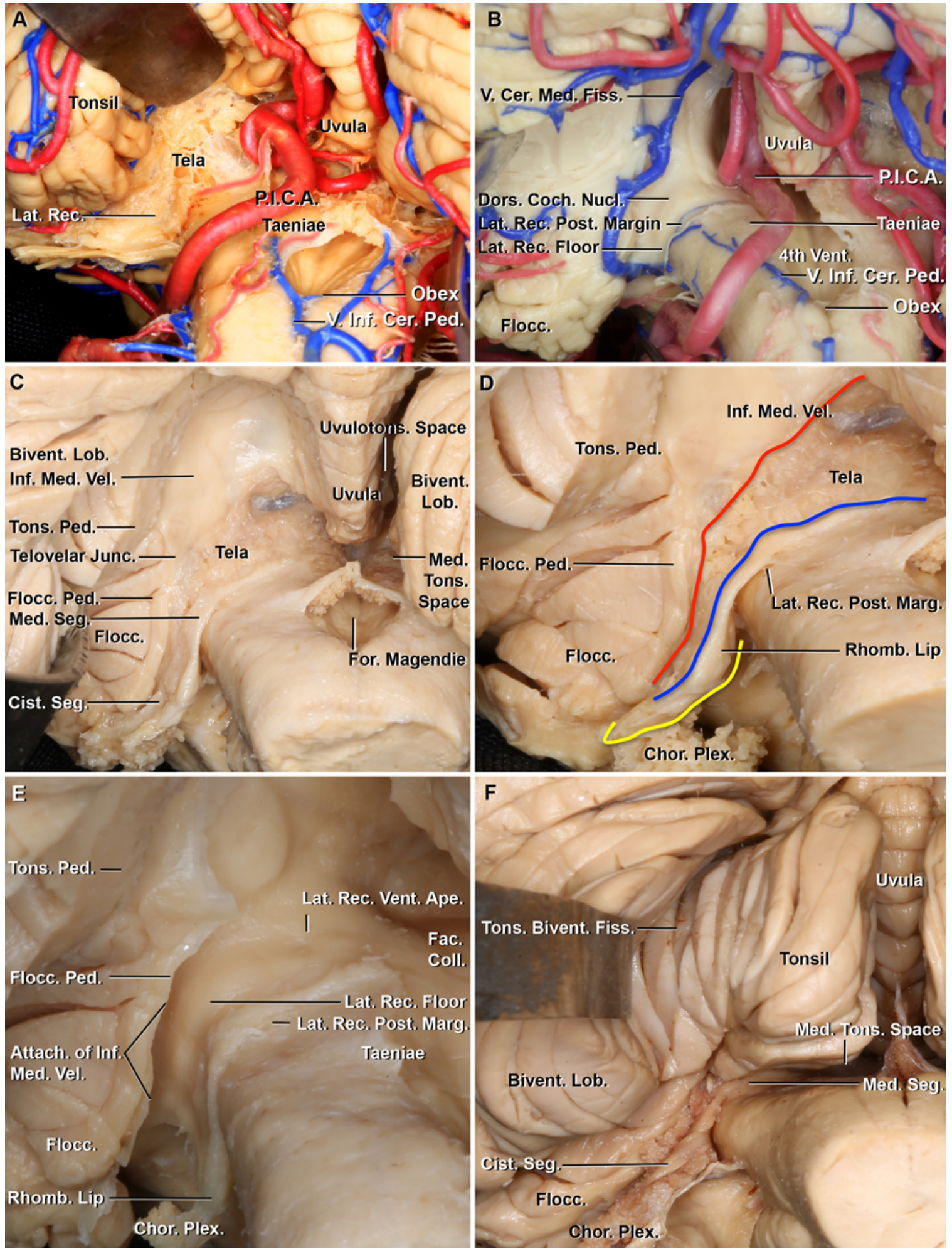

FIG. 3. A: Arterial relationships around the lateral recess. Enlarged posterior view of the left half of the cerebellomedullary fissure with superolateral retraction of the left tonsil. The PICA supplies the medial part of the tela choroidea and the rhomboid lip and courses laterally, dorsal to the medullary and the cisternal segments of the lateral recess in the cerebellomedullary fissure. B: Venous relationships around the lateral recess. Enlarged posterior view of the left half of the cerebellomedullary fissure. The tonsil has been removed. The vein of the cerebellomedullary fissure passes through the lateral recess dorsal to the flocculus. The vein of the inferior cerebellar peduncle courses along the lateral edge of the medulla and passes inferodorsal to the posterior edge of the lateral recess. C: The left tonsillar peduncle has been divided and the tonsil removed. The tonsillar peduncle is located along the superolateral margin of the tonsil. The foccular peduncle connects to the inferior medullary velum without a clear boundary. The tonsillar peduncle is the only neural attachment of the tonsil to the remainder of the cerebellum. FIG. 3. (continued) $\rightarrow$ 
FIG. 3. D: Relationships and borders between the floccular peduncle, tela choroidea, and rhomboid lip around the lateral recess. The red line shows the telovelar junction. The blue line shows the junction between the tela choroidea and the rhomboid lip. The yellow line shows the margin of the rhomboid lip. E: The left tonsil has been removed and the tela and left lateral recess have been opened. The peduncle of the flocculus is located ventral to the tonsillar peduncle. The facial colliculus is a landmark for the safe entry zones in the floor of the fourth ventricle, and it is exposed on the left half of the floor. The attachment of the inferior medullary velum continues until the foramen of Luschka. The dorsal cochlear nucleus makes a small prominence on the dorsal surface of the lateral recess. F: Inferior view. The tonsillobiventral fissure is located between the tonsil and the biventral lobule. It terminates at the level of the cisternal segment dorsally. The medial tonsilar space is the medial part of the tonsillomedullary space. Ape. = aperture; Attach. = attachment; Bivent. = biventral; Cer. = cerebellar, cerebello; Lob. = lobule; Marg. = margin; Med. $=$ medullary, medullo; Tons. = tonsillar; Uvulotons. = uvulotonsilar; Vent. = ventricular, ventricle.

and the inferior cerebellar peduncle (Fig. 4B and C). The vestibular nerve fibers covered the superficial layer of the ventral wall, coursing toward the vestibular nucleus, which was located near the ventricular aperture of the medullary segment of the lateral recess (Fig. 4D and E).

The dorsal and ventral cochlear nuclei formed a smooth prominence on the dorsal surface of the inferior cerebellar peduncle at the floor of the medullary segment of the lateral recess (Fig. 4B). The inferior cerebellar peduncle, a fiber tract connecting the medulla and the cerebellum, ascended along the lateral edge of the medulla under the vestibular nerve fiber and the cochlear nuclei. The facial nerve, after exiting from the facial nucleus, ran deeply through the anterorostral portion of the medullary segment of the lateral recess, under the inferior cerebellar peduncle and adjacent structures (Fig. 4A and F). At the outer margin of the lateral recess, the floccular peduncle communicated between the flocculus and the nodule, which was the lowermost subdivision of the vermis. The tonsillar peduncle, located along the superolateral margin of the tonsil, communicated between the tonsil and uvula of the cerebellar vermis and superiorly with the flocculonodular lobe dorsal to the floccular peduncle. Most of the floccular peduncle fibers ascended along the inferior cerebellar peduncle ventral to the inferior medullary velum and connected to the lateral lemnisci. The floccular peduncle also received afferent fibers from the vestibular nucleus, which was not part of the flocculonodular lobe (Fig. 4A-E). The inferior and middle cerebellar peduncles ran through its deep portions. From the above result, we postulate that a safe incision line for entry into the pons would be parallel to the floccular peduncle (Fig. 4D).

\section{Approaches to the Lateral Recess}

Approximately $140^{\circ}-150^{\circ}$ of the posteroinferior circumference of the lateral recess was exposed in the medial and lateral routes of the transcerebellomedullary fissure approach.

\section{Medial Route of the Transcerebellomedullary Fissure Approach}

After the midline suboccipital approach, opening both the medullotonsillar and uvulotonsillar spaces provided wide exposure of the lateral recess (Fig. 5A and B). We preferred to insert an operative microscope from the contralateral side after sufficient bilateral cerebellomedullary fissure dissection when wide exposure of the lateral recess was required (Fig. 5C). The PICA and its branch supplying the medulla should be preserved during the dissection. Because the vein of the inferior cerebellar peduncle ran along the inferolateral edge of the fourth ventricle, this vein may be a good landmark for following the taeniae, the attachment of the tela choroidea to the medulla, and to reach the ventricular aperture of the lateral recess located at the rostral edge of the taeniae (Fig. 5B-D). Dissection of the telovelar junction and taeniae opened the lateral recess and exposed the fourth ventricle floor (Fig. 5D). The stria medullaris, composed of whitish fibers, ran horizontally into the lateral recess. Even the lower cranial nerves in the cerebellomedullary cistern could be sufficiently exposed from the midline (Fig. 5E and F).

\section{Lateral Route of the Transcerebellomedullary Fissure Approach}

After removing the lateral rim of the foramen magnum, such as in the transcondylar fossa approach, opening the cerebellomedullary fissure exposed not only the cisternal, but also the medullary segment of the lateral recess from the posteroinferior side (Fig. 6A and B). In this posteroinferior route, it was possible to obtain wide exposure of the whole ipsilateral lateral recess and area around the median sulcus, while sufficient cerebellomedullary fissure dissection also allows for more gentle cerebellar retraction. Care should be taken not to injure the vein of the cerebellomedullary fissure in the upper ventral side of the lateral recess (Fig. 6C and D). To open the lateral recess, the telovelar junction was incised or detached step by step from the cisternal to the medullary segment of the lateral recess (Fig. $6 \mathrm{E})$. An additional incision of the taeniae up to the foramen of Magendie exposed the whole ipsilateral floor of the fourth ventricle, including the facial colliculus (Fig. 6F).

\section{Discussion}

\section{Anatomical Definition of the Lateral Recess and Rhomboid Lip}

The anatomical terms "lateral recess" and "rhomboid lip" were described as far back as the $1900 \mathrm{~s},{ }^{4}$ but both still lack clear definitions. The latest edition of Gray's Anatomy also does not describe the detailed definition of the lateral recess itself. ${ }^{33}$ Although several papers have investigated this region, the components and definitions of the lateral recess and rhomboid lip have been insufficiently clarified. In the present study, the lateral recess was divided into 2 parts for clear anatomical description. In addition, microscopic observation was used to attempt to clarify the borders between the rhomboid lip, inferior medullary velum, and tela choroidea. The telovelar junction, the boundary between the tela choroidea and inferior medullary velum, can be easily identified with a microscope, and is a good intraoperative landmark for determining how far the fissure has been opened. ${ }^{28,30}$ 

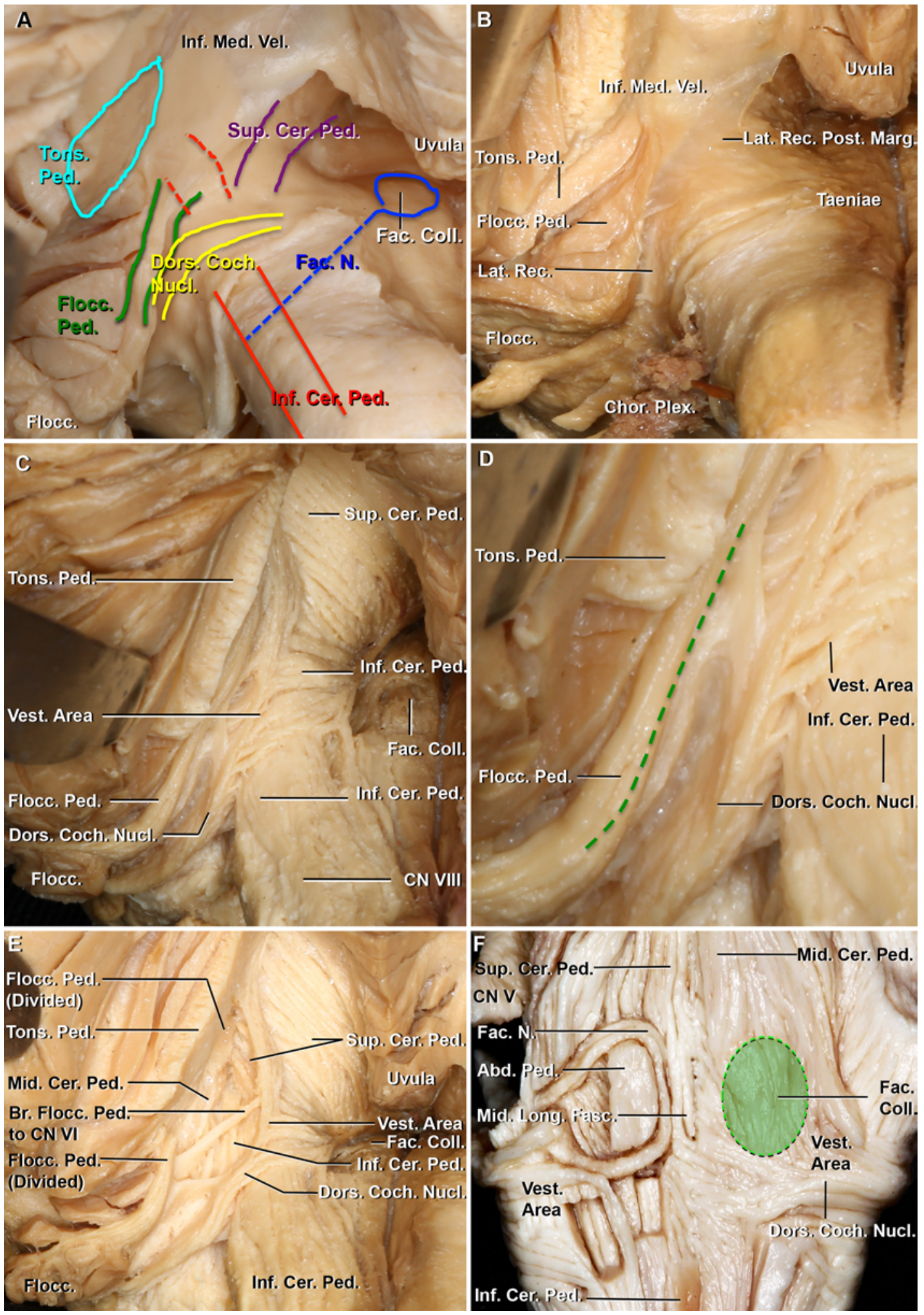

FIG. 4. A: Inferior posterior view. The relationships of the neural structures around the lateral recess after opening the left lateral recess. The solid blue line circle shows the facial colliculus, and the broken blue line shows the course of the facial nerve ventral to the inferior cerebellar peduncle. The red lines indicate the inferior cerebellar peduncle, which runs dorsolateral on the medulla. The green lines show the course of the floccular peduncle, which runs dorsal to the flocculus. The yellow lines show the dorsal cochlear nucleus, which is seen as a prominence on the ventral wall of the lateral recess. The purple lines show the rostromedial course of the superior cerebellar peduncle on the lateral wall of the fourth ventricle. The sky blue oval shows the location of the tonsillar peduncle rostral to the floccular peduncle. FIG. 4. (continued) $\rightarrow$ 
FIG. 4. B-D: Step-by-step fiber dissection. In B, the left lateral recess has been opened. The floccular peduncle is located caudal to the tonsillar peduncle. The inferior medullary velum attaches to the caudal margin of the floccular peduncle and the flocculus. Panel $\mathrm{C}$ shows the superficial layer of the lateral recess in fiber dissection. The floccular peduncle runs rostomedially, caudal to the tonsillar peduncle. The vestibular area is located just caudal to the floccular peduncle. The facial colliculus is seen on the floor of the fourth ventricle. An enlarged view is shown in $\mathrm{D}$. The dorsal cochlear nucleus is located in the vestibular area where it forms a prominence. The space between the floccular peduncle and the dorsal cochlear nucleus is the thin vestibular area. The broken green line shows the postulated safe incision line for entry into the pons. E: Deep layer of the lateral recess in the left lateral recess. The floccular peduncle has been partially removed. The middle cerebellar peduncle is situated ventral to the floccular peduncle in the lower pons. The superior cerebellar peduncle is located medial and ventral to the upper part of the floccular peduncle. The inferior cerebellar peduncle is located medial to the floccular peduncle and ventral to the vestibular area in the lateral recess. F: Fiber dissection on the floor of the fourth ventricle in the posterior view. The right side shows the superficial layer, and the left shows the deeper layer in fiber dissection. The green oval shows the facial colliculus. Almost all of the lateral recess is covered by the vestibular area. The facial nerve courses around the abducens nucleus. The superior cerebellar peduncle courses rostral to the lateral recess. Abd. = abducens; $\mathrm{Br}$. = branch; Fasc. = fasciculus; Long. = longitudinal; N. = nerve; Post. = posterior; Vest. $=$ vestibular.

\section{Surgical Approaches to the Lateral Recess}

Several approaches can be used for exposing the lateral recess, including the anterior endoscopic approach,, 932 presigmoid approach via the cerebellopontine angle laterally, ${ }^{17,15}$ and variations of the transcerebellomedullary fissure approach through the cerebellomedullary fissure inferiorly. ${ }^{23,26,29}$ Of these, only the transcerebellomedullary fissure approach can provide easy access to both the medullary and cisternal segments of the lateral recess; the medullary segment is difficult to access through the other approaches. In addition, the operative field obtained with the anterior endoscopic approach is deep, and the brainstem, major arteries, and cranial nerves in front of the lateral recess can be obstructed. The presigmoid approach requires laborious mastoidectomy, and its exposure is limited by the sigmoid sinus and cranial nerves. The transcerebellomedullary fissure approach provides wide exposure of the lateral recess at around $140^{\circ}-150^{\circ}$ of its posteroinferior circumference, without obstruction by cranial nerves.

The transcerebellomedullary fissure approach includes the medial route inferomedially ${ }^{22,25,29}$ and the lateral route inferolaterally. ${ }^{13,26}$ Initially, the medial route was proposed to overcome the insufficiency of the lateral exposure around the lateral recess through the conventional transvermian approach. ${ }^{19,21,22,25,34}$ To obtain a wide and direct operative view, we prefer to open the bilateral cerebellomedullary fissure, when we are present on the side of the patient that is contralateral to the tumor. The conventional retrosigmoid approach can provide lateral exposure of the cisternal segment of the lateral recess via the cerebellopontine angle without opening of the cerebellomedullary fissure, ${ }^{7}$ but cerebellomedullary fissure dissection can provide wide exposure of the whole lateral recess, including its medullary segment inferolaterally, while ameliorating cerebellar retraction. ${ }^{13,26}$ Removal of the lateral foramen magnum, such as in the transcondylar fossa approach, is useful to solve the problem of the deep and narrow surgical field. ${ }^{24}$ With an inferolateral visual axis to the lateral recess, obstructions on the medial side, such as the tonsil and biventral lobule of the cerebellum, can be easily retracted after cerebellomedullary fissure dissection, and obstructions on the lateral side, such as the lateral rim of the foramen magnum, including the jugular tubercle, can be avoided using the transcondylar fossa approach. These routes provide, respectively, medial-to-lateral and lateralto-medial access to the lateral recess, and when combined, it is possible to expose approximately $140^{\circ}-150^{\circ}$ of the circumference of the lateral recess inferiorly.

\section{Entry Into the Brainstem Around the Lateral Recess}

With recent advances in brainstem surgery, the following areas around the lateral recess have been reported as "safe entry zones" for the brainstem: 1) the area acoustica at the fourth ventricle, ${ }^{5}$ 2) the inferior cerebellar peduncle from the cerebellopontine angle ${ }^{7}$ or from the tonsillar peduncle, ${ }^{17}$ and 3) the middle cerebellar peduncle from the cerebellopontine angle. ${ }^{3}$ Depending on the location of the lesion and preoperative symptoms, a vestibular peduncle incision may cause dizziness/vertigo, postural instability, and eye movement disorders; ${ }^{10}$ an inferior cerebellar peduncle incision may cause ipsilateral hemiataxia; and a middle cerebellar peduncle incision may cause ipsilateral truncal ataxia, limb ataxia, dysmetria, dysdiadochokinesia, and axial lateropulsion.

In this study, we present the floccular peduncle region as a possible entry site to the lower pons. The routes via the floccular peduncle or via the area between the floccular peduncle and the vestibular area may be safe access routes to lesions located at the lateral lower pons posteriorly. The floccular peduncle is located just rostral to the attachment of the inferior medullary velum to the flocculus. Care should be taken with regard to the lower cranial nerves, dorsal cochlear nucleus located on the ventral wall of the medullary segment, and vein of the cerebellomedullary fissure to prevent injury. The vein of the cerebellomedullary fissure runs laterally along the cerebellomedullary fissure to join the vein of the middle cerebellar peduncle or the vein of the cerebellopontine fissure, which may provide a good landmark to identify the floccular peduncle. ${ }^{27,28}$ It is theoretically possible to access the tonsillar peduncle without incising the lateral recess because the tonsillar peduncle is located just lateral to and outside of the lateral recess. However, because incision of the inferior medullary velum or tela choroidea does not cause any postoperative complications, opening the lateral recess, and identifying the anatomical structures inside the lateral recess, such as the cochlear nucleus, may be advisable before accessing the internal brainstem. ${ }^{19,23}$

The flocculus receives input from the vestibule, which projects to the medial and lateral vestibular nuclei of the brainstem, ${ }^{12}$ and is involved in balance, ${ }^{31}$ eye movement,${ }^{8,37}$ and vestibular functions, such as the vestibular-ocular re- 

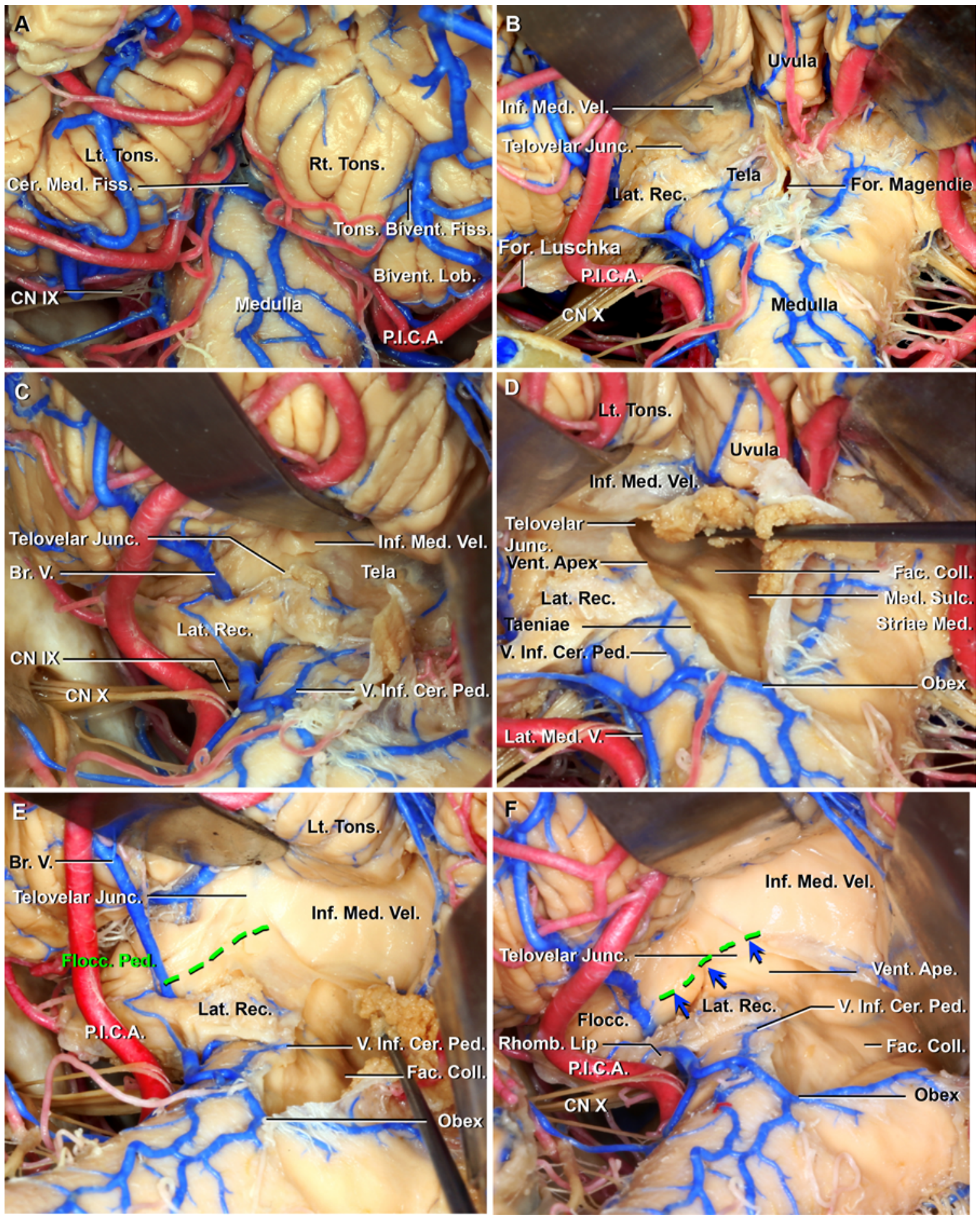

FIG. 5. Step-by-step cadaveric dissection through the medial route in the cerebellomedullary fissure approach. A: Posterior view of the midline suboccipital craniotomy. The cerebellomedullary fissure is adherent to the tonsil. The tonsillobiventral fissure is the space between the tonsil and the biventral lobule. The medullotonsillar space is located between the medulla and the tonsil. B: Opening the cerebellomedullary cistern by retracting the bilateral tonsils laterally exposes both segments of the lateral recess and the telovelar junction. The uvulotonsilar space is located between the uvula and the tonsil. C: Inferomedial surgical view. The lateral part of the fourth ventricle and the lateral recess are exposed. This provides access to the telovelar junction and the lateral recess. The bridging vein runs around the lateral recess. D: Posterior view. The dissection of the taeniae up to the telovelar junction exposes the entrance of the medullary segment of the lateral recess, facial colliculus, median sulcus, and stria medullaris on the floor of the fourth ventricle. E: Inferomedial surgical view after exposing the entrance of the medullary segment. At the exterior end of the lateral recess, the inferior medullary velum forms the floccular peduncle, which joins the flocculus. The broken green line shows the course of the floccular peduncle and the postulated safe incision for entry into the pons. FIG. 5. (continued) $\rightarrow$ 
FIG. 5. F: Inferior medial surgical view after exposing both segments of the lateral recess by removing the tela choroidea and choroid plexus. The small blue arrows show the attachment of the inferior medullary velum to the dorsal margin of the flocculus. The broken green line shows the course of the floccular peduncle. This view provides good access to the lower pons through the floccular peduncle. The lower cranial nerves are observed in the cerebellomedullary cistern. Br. = bridging; Lt. = light; Med. = median, medullares, medullary; Rt. = right; Sulc. = sulcus; Tons. = tonsil, tonsilo; Vent. = ventricular.
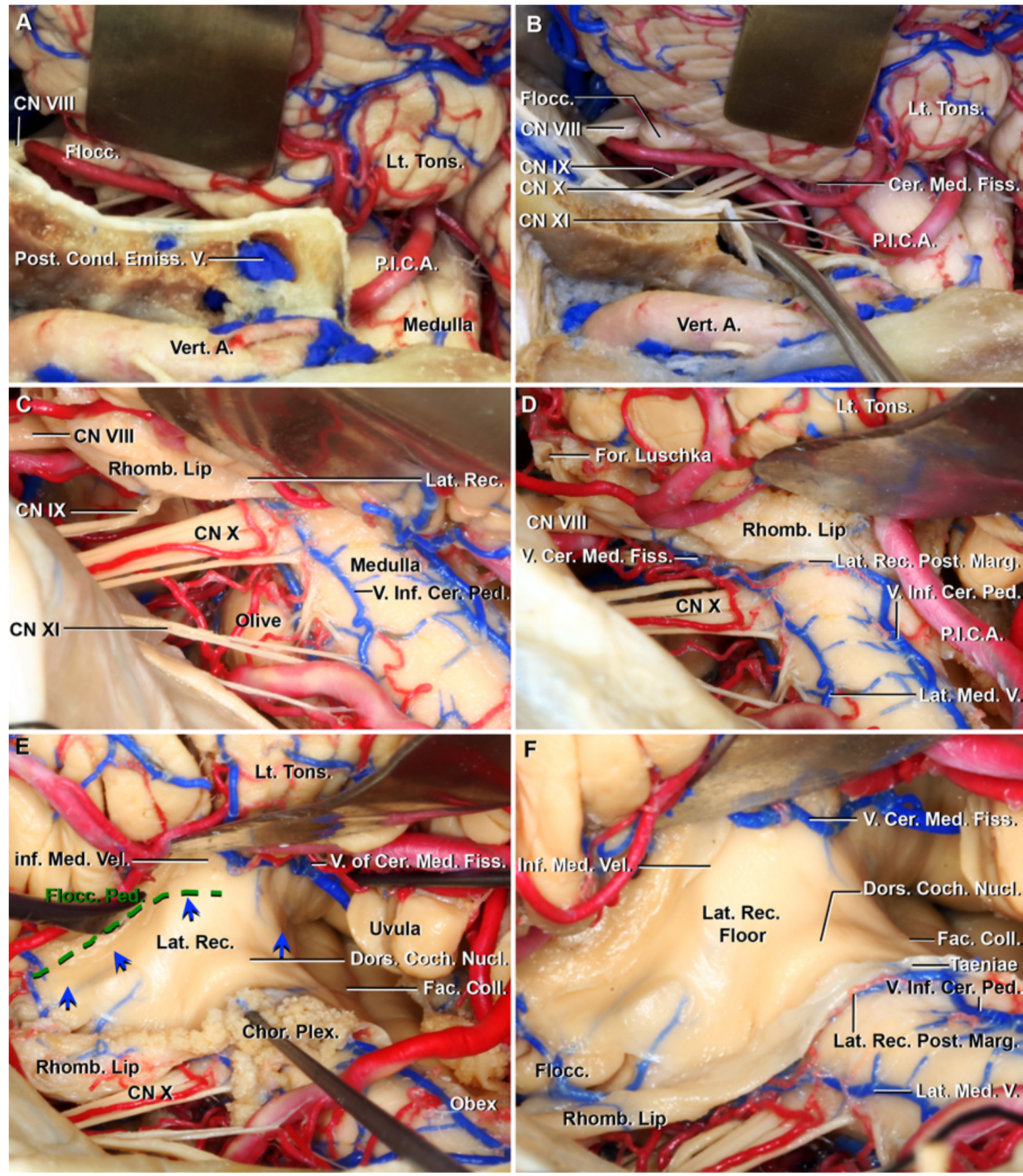

FIG. 6. Step-by-step cadaveric dissection through the lateral route in the cerebellomedullary fissure approach. A: A left suboccipital craniotomy was performed. The condylar fossa superior to the posterior condylar canal blocks the view of the cerebellomedullary cistern and the lower cranial nerves. B: The condylar fossa is drilled extradurally and removed. The jugular tubercle located above the hypoglossal canal is drilled away. C: Lateral posteroinferior view of the lateral portion of the fourth ventricle. After the left tonsil is retracted, the cisternal segment and a part of the medullary segment of the lateral recess with the rhomboid lip and the lower cranial nerves are exposed. D: After dissection of the cerebellomedullary fissure, the tonsil is easily raised and both parts of the lateral recess are exposed. The vein of the cerebellomedullary fissure and the vein of the inferior cerebellar peduncle run around the lateral recess. FIG. 6. (continued) $\rightarrow$ 
FIG. 6. E: After dissection of the telovelar junction, the whole lateral recess is exposed. The small blue arrows show the attachment of the inferior medullary velum to the dorsal margin of the flocculus. The broken green line shows the course of the floccular peduncle and the postulated safe incision into the pons. The facial colliculus is exposed on the floor of the fourth ventricle. The vein of the cerebellomedullary fissure does not run inside the lateral recess. The dorsal cochlear nucleus is located on the ventral wall of the medullary segment of the lateral recess. F: Enlarged view after removal of the choroid plexus. Both segments of the lateral recess are exposed. The dorsal cochlear nucleus is located caudal to the floccular peduncle. Cond. = condylar; Emiss. = emissary; Med. = medullary.

flex. ${ }^{2,11,35}$ There are few reports concerning disorders due to intraoperative damage of the flocculus, but injury of the flocculus may include a risk of developing eye movement disorder, nystagmus, or vestibular-ocular reflex disorder. ${ }^{3,7}$ As written in previous reports, it is necessary to select an entry site near the brainstem surface for access, based on the location of the lesion and preoperative symptoms. We have postulated that a safe incision line for entry into the pons would be parallel line to the floccular peduncle in both cerebellomedullary fissure approaches (Figs. 5E and $6 \mathrm{E})$. The floccular peduncle may be a useful option for approaching lesions inside the lower pons in appropriately selected patients.

\section{Conclusions}

The lateral and medial routes of the transcerebellomedullary fissure approach provided wide exposure around the lateral recess in this cadaver study. The floccular peduncle may be a good option for approaching lesions inside the lower pons in appropriately selected patients, based on preoperative clinical symptoms and the location of the lesion.

\section{Acknowledgments}

The authors wish to thank Robin Barry, MA, for her assistance with the preparation of the illustrations, and Jessica Striley, BS, for her editorial assistance. This work was supported by the University of Florida Foundation.

\section{References}

1. Abe H, Rhoton AL Jr: Microsurgical anatomy of the cochlear nuclei. Neurosurgery 58:728-739, 2006

2. Anzai M, Kitazawa H, Nagao S: Effects of reversible pharmacological shutdown of cerebellar flocculus on the memory of long-term horizontal vestibulo-ocular reflex adaptation in monkeys. Neurosci Res 68:191-198, 2010

3. Bertalanffy H, Benes L, Miyazawa T, Alberti O, Siegel AM, Sure U: Cerebral cavernomas in the adult. Review of the literature and analysis of 72 surgically treated patients. Neurosurg Rev 25:1-55, 2002

4. Blake JA: The roof and lateral recesses of the fourth ventricle, considered morphologically and embryologically. J Comp Neurol 10:79-108, 1900

5. Bricolo A: Surgical management of intrinsic brain stem gliomas. Oper Tech Neurosurg 3:137-154, 2000

6. Deshmukh VR, Figueiredo EG, Deshmukh P, Crawford NR, Preul MC, Spetzler RF: Quantification and comparison of telovelar and transvermian approaches to the fourth ventricle. Neurosurgery 58 (4 Suppl 2):ONS-202-ONS-207, 2006

7. Deshmukh VR, Rangel-Castilla L, Spetzler RF: Lateral inferior cerebellar peduncle approach to dorsolateral medullary cavernous malformation. J Neurosurg 121:723-729, 2014

8. Dufossé M, Ito M, Miyashita Y: Functional localization in the rabbit's cerebellar flocculus determined in relationship with eye movements. Neurosci Lett 5:273-277, 1977
9. Funaki T, Matsushima T, Peris-Celda M, Valentine RJ, Joo W, Rhoton AL Jr: Focal transnasal approach to the upper, middle, and lower clivus. Neurosurgery 73 (2 Suppl Operative):ons155-ons191, 2013

10. Giliberto G, Lanzino DJ, Diehn FE, Factor D, Flemming KD, Lanzino G: Brainstem cavernous malformations: anatomical, clinical, and surgical considerations. Neurosurg Focus 29(3):E9, 2010

11. Ito M: Cerebellar control of the vestibulo-ocular reflexaround the flocculus hypothesis. Annu Rev Neurosci 5:275296, 1982

12. Johnston TB: A note on the peduncle of the flocculus and the posterior medullary velum. J Anat 68:471-479, 1934

13. Kawashima M, Matsushima T, Nakahara Y, Takase Y, Masuoka J, Ohata K: Trans-cerebellomedullary fissure approach with special reference to lateral route. Neurosurg Rev 32:457-464, 2009

14. Kawashima M, Takase Y, Matsushima T: Surgical treatment for vertebral artery-posterior inferior cerebellar artery aneurysms: special reference to the importance of the cerebellomedullary fissure dissection. J Neurosurg 118:460-464, 2013

15. Komune N, Yagmurlu K, Matsuo S, Miki K, Abe H, Rhoton AL Jr: Auditory brainstem implantation: anatomy and approaches. Neurosurgery 11 (Suppl 2):306-321, 2015

16. Kyoshima K, Kobayashi S, Gibo H, Kuroyanagi T: A study of safe entry zones via the floor of the fourth ventricle for brain-stem lesions. Report of three cases. J Neurosurg 78:987-993, 1993

17. Lawton MT, Quiñones-Hinojosa A, Jun P: The supratonsillar approach to the inferior cerebellar peduncle: anatomy, surgical technique, and clinical application to cavernous malformations. Neurosurgery 59 (4 Suppl 2): ONS244-ONS252, 2006

18. Matsushima K, Yagmurlu K, Kohno M, Rhoton AL Jr: Anatomy and approaches along the cerebellar-brainstem fissures. J Neurosurg 124:248-263, 2016

19. Matsushima T: Microsurgical Anatomy and Surgery of the Posterior Cranial Fossa. Tokyo: Springer, 2015

20. Matsushima T, Abe H, Kawashima M, Inoue T: Exposure of the wide interior of the fourth ventricle without splitting the vermis: importance of cutting procedures for the tela choroidea. Neurosurg Rev 35:563-572, 2012

21. Matsushima T, Fukui M, Inoue T, Natori Y, Baba T, Fujii K: Microsurgical and magnetic resonance imaging anatomy of the cerebello-medullary fissure and its application during fourth ventricle surgery. Neurosurgery 30:325-330, 1992

22. Matsushima T, Inoue T, Inamura T, Natori Y, Ikezaki K, Fukui M: Transcerebellomedullary fissure approach with special reference to methods of dissecting the fissure. J Neurosurg 94:257-264, 2001

23. Matsushima T, Kawashima M, Inoue K, Matsushima K, Miki $\mathrm{K}$ : Exposure of the wide cerebellomedullary cisterns for vascular lesion surgeries in the CMCs: Opening of unilateral cerebellumedullary fissures combined with lateral foramen magnum approach. World Neurosurg 82:e615-e621, 2014

24. Matsushima T, Kawashima M, Masuoka J, Mineta T, Inoue T: Transcondylar fossa (supracondylar transjugular tubercle) approach: anatomic basis for the approach, surgical procedures, and surgical experience. Skull Base 20:83-91, 2010 
25. Matsushima T, Matsukado K, Inoue T, Fukui M: Part 5: Midline suboccipital approach to treatment of lesions in or around the fourth ventricle: special reference to the transcerebellomedullary approach. Nerv Syst Child 25:173-177, 2000 (Jpn)

26. Matsushima T, Ohata K: Anatomy of the fourth ventricle and trans-cerebellomedullary fissure approach: medial route and lateral route, in Hongo K (ed): Surgical Anatomy for Microneurosurgery XVIII. Tokyo: SciMed, 2005, pp 39-48 (Jpn)

27. Matsushima T, Rhoton AL Jr, de Oliveira E, Peace D: Microsurgical anatomy of the veins of the posterior fossa. J Neurosurg 59:63-105, 1983

28. Matsushima T, Rhoton AL Jr, Lenkey C: Microsurgery of the fourth ventricle: Part 1. Microsurgical anatomy. Neurosurgery 11:631-667, 1982

29. Mussi ACM, Rhoton AL Jr: Telovelar approach to the fourth ventricle: microsurgical anatomy. J Neurosurg 92:812-823, 2000

30. Nakahara Y, Matsushima T, Hiraishi T, Takao T, Funaki T, Masuoka J, et al: Importance of awareness of the rhomboid lip in microvascular decompression surgery for hemifacial spasm. J Neurosurg 119:1038-1042, 2013

31. Park HK, Kim JS, Strupp M, Zee DS: Isolated floccular infarction: impaired vestibular responses to horizontal head impulse. J Neurol 260:1576-1582, 2013

32. Seker A, Inoue K, Osawa S, Akakin A, Kilic T, Rhoton AL Jr: Comparison of endoscopic transnasal and transoral approaches to the craniovertebral junction. World Neurosurg 74:583-602, 2010

33. Standring S (ed): Gray's Anatomy, ed 41. Amsterdam: Elsevier, 2016

34. Tanriover N, Ulm AJ, Rhoton AL Jr, Yasuda A: Comparison of the transvermian and telovelar approaches to the fourth ventricle. J Neurosurg 101:484-498, 2004

35. Watanabe E: Neuronal events correlated with long-term adaptation of the horizontal vestibulo-ocular reflex in the primate flocculus. Brain Res 297:169-174, 1984
36. Yagmurlu K, Rhoton AL Jr, Tanriover N, Bennett JA: Threedimensional microsurgical anatomy and the safe entry zones of the brainstem. Neurosurgery 10 (Suppl 4):602-620, 2014

37. Zee DS, Yamazaki A, Butler PH, Gücer G: Effects of ablation of flocculus and paraflocculus of eye movements in primate. J Neurophysiol 46:878-899, 1981

38. Ziyal IM, Sekhar LN, Salas E: Subtonsillar-transcerebellomedullary approach to lesions involving the fourth ventricle, the cerebellomedullary fissure and the lateral brainstem. Br J Neurosurg 13:276-284, 1999

\section{Disclosures}

The authors report no conflict of interest concerning the materials or methods used in this study or the findings specified in this paper.

\section{Author Contributions}

Conception and design: T Matsushima, Akiyama, K Matsushima, Rhoton. Acquisition of data: T Matsushima, Akiyama, Nunez, Matsuo. Analysis and interpretation of data: Akiyama, Nunez, Matsuo. Drafting the article: T Matsushima, Akiyama, K Matsushima. Critically revising the article: T Matsushima, Akiyama, K Matsushima. Reviewed submitted version of manuscript: Akiyama, Kondo. Approved the final version of the manuscript on behalf of all authors: T Matsushima. Statistical analysis: T Matsushima, Akiyama. Administrative/technical/material support: Akiyama, Nunez, Matsuo. Study supervision: T Matsushima, Akiyama, Kondo, Arai.

\section{Correspondence}

Toshio Matsushima, Neuroscience Center, Fukuoka Sanno Hospital, 3-6-45, Momochihama, Sawara-ku, Fukuoka 814-0001, Japan. email: matsuto@kouhoukai.or.jp. 